\title{
Toluene Diisocyanate Increases Airway Responsiveness to Substance P and Decreases Airway Neutral Endopeptidase
}

\author{
Dean Sheppard, James E. Thompson, Linda Scypinski, Daniel Dusser, Jay A. Nadel, and D. Benjamin Borson \\ Cardiovascular Research Institute, The Lung Biology Center, and the Departments of Medicine and Physiology, \\ University of California, San Francisco, California 94110
}

\section{Abstract}

Substance $P$ and related tachykinins contribute to the airway hyperresponsiveness caused by toluene diisocyanate (TDI) in guinea pigs. Neutral endopeptidase (NEP) is an important modulator of substance $P$-induced responses. To test the hypothesis that exposure to TDI would increase responsiveness to substance $P$ by inhibiting activity of this enzyme, we determined the dose of substance $P$ required to increase pulmonary resistance by $200 \%$ above baseline $\left(\mathrm{PD}_{200}\right)$ before and after administration of the pharmacologic inhibitor phosphoramidon in guinea pigs studied $1 \mathrm{~h}$ after a 1-h exposure to air or 3 ppm TDI. TDI exposure increased responsiveness to substance P significantly. However, phosphoramidon caused a significantly greater leftward shift of the substance $P$ dose-response curve in air-exposed animals than it did in TDI-exposed animals, so that after phosphoramidon, mean values of $\mathbf{P D}_{200}$ in animals exposed to air or TDI did not differ. Tracheal NEP activity was significantly less after exposure to TDI than after exposure to air, whereas activity in the esophagus was the same in both groups. These results suggest that TDI exposure increases the bronchoconstrictor responsiveness of guinea pigs to substance $P$, in large part through inhibition of airway NEP.

\section{Introduction}

Tachykinins are small peptides that are important mediators of inflammation in the airways of many mammals, including humans (1-3). Both exogenously administered and endogenously released tachykinins are stimuli that contract airway smooth muscle $(2,3)$, increase airway vascular permeability (2-4), increase secretion of airway mucus (5), and potentiate cholinergic neurotransmission to airway smooth muscle (6). We have shown that tachykinins also play a critical role in the increase in in vivo responsiveness of airway smooth muscle that follows exposure to the inflammatory stimulus toluene diisocyanate (TDI) ${ }^{1}$ in guinea pigs (7).

Address all correspondence to Dr. Dean Sheppard, Chest Service, Room 5K1, San Francisco General Hospital, 1001 Potrero Avenue, San Francisco, CA 94110.

Received for publication 12 June 1987 and in revised form 21 October 1987.

1. Abbreviations used in this paper: NEP, neutral endopeptidase; $\mathrm{PD}_{200}$, provocative dose of substance $\mathrm{P}$ required to increase $\mathbf{R}_{\mathbf{L}}$ by $200 \%$ above baseline; $\mathrm{PD}_{200}$ ratio, ratio of $\mathrm{PD}_{200}$ before phosphoramidon to $\mathrm{PD}_{200}$ after phosphoramidon; $\mathrm{R}_{\mathrm{L}}$, pulmonary resistance; TDI, toluene diisocyanate.

\section{J. Clin. Invest.}

(c) The American Society for Clinical Investigation, Inc.

0021-9738/88/04/1111/05 \$2.00

Volume 81, April 1988, 1111-1115
Recent evidence from in vitro studies suggests that the effects of tachykinins are greatly influenced by the presence of neutral endopeptidase EC 3.4.24.11 (NEP, originally called enkephalinase because of its effect in degrading enkephalins), a cell membrane-bound peptidase that can cleave tachykinins $(8,9)$. Thus, inhibition of this enzyme has been shown to markedly potentiate the effects of the tachykinin substance $P$ on macromolecule secretion from ferret trachea (5), on contraction of ferret airway smooth muscle (10), and on cholinergic neurotransmission $(6,10)$. Little is known, however, about the role of NEP in modulating responses to tachykinins in vivo, or the significance of alterations in activity of this enzyme to conditions where tachykinin responsiveness is increased. Because NEP is a membrane-bound enzyme that is present in airway tissue (11), it might be susceptible to degradation in association with airway epithelial injury or inflammation. Because inhalation of TDI causes acute airway epithelial injury and inflammation (12), we hypothesized that TDI might potentiate the bronchoconstrictor effects of tachykinins, such as substance $P$, by inactivating this enzyme. To test this hypothesis, we examined the effects of pharmacologic inhibition of NEP by phosphoramidon on bronchoconstrictor responsiveness to substance $P$ in guinea pigs exposed to TDI or to clean air. Because phosphoramidon causes a significant increase in substance $P$ responsiveness in normal guinea pigs (unpublished observation), we reasoned that if TDI exposure inactivated NEP it would increase substance $P$ responsiveness, and would decrease the potentiation of substance $P$ responsiveness caused by phosphoramidon. To confirm that any effects we observed in vivo were associated with enzyme inactivation, we also measured NEP activity ex vivo in the trachea and esophagus of animals exposed to TDI or to air.

\section{Methods}

Male Hartley-outbred guinea pigs (Charles River Breeding Laboratories, Wilmington, MA) weighing from 356 to $538 \mathrm{~g}$ were housed in hanging steel mesh cages and fed standard guinea pig chow (Purina Lab Chow; Ralston-Purina Co., St. Louis, MO) and water ad libitum. All protocols were approved by the Committee on Animal Research of the University of California, San Francisco.

15 animals were exposed to filtered air $(n=6)$ or $3 \mathrm{ppm}$ TDI $(n=9)$ for $1 \mathrm{~h}$. Each animal was then anesthetized with $100 \mathrm{mg} / \mathrm{kg}$ alpha-chloralose (Sigma Chemical Co., St. Louis, MO) given intraperitoneally. Additional injections were given as necessary. After additional local lidocaine anesthesia, a tracheal cannula was inserted and a 23-gauge polyethylene catheter was introduced into the right carotid artery for monitoring arterial blood gases and $\mathrm{pH}$, and a 30 -gauge polyethylene catheter was introduced into a jugular vein for administration of intravenous medications. A fluid-filled polyethylene catheter with one side hole was inserted into the esophagus to measure esophageal pressure as an approximation of pleural pressure and was positioned to maximize the pressure signal and minimize the pressure change caused by cardiac contraction. The animal was then placed in a whole body pressure 
plethysmograph and ventilated with a small animal respirator (model 683; Harvard Apparatus Co., Inc., The Ealing Corp., South Natick, MA) at a frequency of 90 breaths/min. The tidal volume was adjusted to yield an arterial pH between 7.30 and 7.50. Transpulmonary pressure (the difference between tracheal and esophageal pressure) was measured with a Sanborn 268B transducer (Hewlett-Packard Co., Palo Alto, CA). Tidal volume was measured by a differential pressure transducer (MP-45; Validyne Engineering Corp., Northridge, CA) connected to the plethysmograph, and this signal was electronically differentiated to calculate flow. All pressure and volume signals were in phase up to $7 \mathrm{~Hz}$ at the flow rates and volumes used. Total pulmonary resistance $\left(R_{L}\right)$ was calculated using the method of Amdur and Mead (13) with an analogue computer (model 6; Buxco Electronics Inc., Sharon, CT), and values were confirmed by hand calculation from the primary signals on several occasions.

$1 \mathrm{~h}$ after the end of exposure to air or to TDI, a dose-response curve measuring the effects of intravenous administration of increasing doses of substance $P$ on $R_{L}$ was performed. $R_{L}$ was measured continuously before and after bolus administration of $0.1-0.2 \mathrm{ml}$ of substance $P$ (Bachem, Torrance, CA) dissolved in isotonic saline and $1 \%$ acetic acid. Substance $\mathbf{P}$ was given at 2 -min intervals in increasing doses beginning with $0.05 \mu \mathrm{g}$ until $R_{\mathrm{L}}$ increased by at least $200 \%$ above baseline. After each injection the jugular catheter (dead space $\sim 0.07$ $\mathrm{ml}$ ) was flushed with $0.1 \mathrm{ml}$ of isotonic heparinized saline $(1,000 \mathrm{U}$ heparin/10 ml). $30 \mathrm{~min}$ later phosphoramidon (Peninsula Laboratories Inc., Belmont, CA) was administered as a single dose $(0.5 \mathrm{mg}$ in 1 $\mathrm{ml} 0.5 \%$ albumin in isotonic saline). $5 \mathrm{~min}$ after administration of phosphoramidon the dose-response curve to substance $P$ was performed again as described above. The dose and timing of phosphoramidon were chosen on the basis of preliminary experiments.

TDI and air exposures were performed in identical 22-liter flowthrough acrylic chambers. The TDI chamber was lined with a Teflon overlay (Cole-Parmer Instrument Co., Chicago, IL). TDI vapor was generated by passing a metered flow of dry, filtered air through the head space of a flask containing TDI (80\% 2, 4 TDI/20\% 2, 6 TDI, Aldrich Chemical Co., Milwaukee, WI). The flask was maintained at $38^{\circ} \mathrm{C}$ in a water bath. TDI vapor was diluted with filtered air in a glass mixing chamber before it entered the exposure chamber. The exposure and generation systems were enclosed in a fume hood and all tubing in contact with the gas mixture was made of glass or Teflon. The TDI concentration in the chamber was measured at least twice during each 1-h exposure by a modification of the method described by Marcali (14). Animals were exposed to air under similar conditions of flow, temperature, and humidity. The mean $( \pm \mathrm{SD})$ chamber temperature was $25.6 \pm 1.0^{\circ} \mathrm{C}$ and the relative humidity was $15.7 \pm 3.8 \%$. The mean ( \pm SD) TDI concentration was $3.04 \pm 0.10 \mathrm{ppm}$.

To determine whether TDI exposure altered the activity of airway NEP, we measured enzyme activity in the tracheas of six additional animals exposed to TDI $(3.00 \pm 0.16 \mathrm{ppm})$ and in six animals exposed to air. To determine whether the effect of TDI was localized to the airway, we also measured activity in the esophagus of the same animals. Each animal was exposed to air or TDI for $1 \mathrm{~h}$ as described above. $1 \mathrm{~h}$ later the animal was killed with a lethal injection of pentobarbital $(390 \mathrm{mg} / \mathrm{kg}$ i.p.) and was then perfused systemically through the aorta with Hepes buffer ( $25 \mathrm{mM}$ in isotonic saline, $\mathrm{pH} 7.4$ ) for 2.5 min at a perfusion pressure of $100 \mathrm{mmHg}$ to clear the systemic circulation of blood. The entire trachea and esophagus were then removed rapidly, cleaned, and stored in dry polypropylene tubes at $-70^{\circ} \mathrm{C}$ for later determination of tissue NEP activity.

We measured NEP activity using a modification of the procedure of Llorens and co-workers (15). We minced segments of trachea and esophagus (up to $200 \mathrm{mg}$ ) in $2 \mathrm{ml}$ of $50 \mathrm{mM}$ Hepes, $125 \mathrm{mM} \mathrm{NaCl}$ (pH 7.4), and homogenized the segments in a polytron for $10 \mathrm{~s}$. We then incubated duplicate samples of $50 \mu \mathrm{l}$ of homogenate (or an appropriate dilution) at $37^{\circ} \mathrm{C}$ for $40 \mathrm{~min}$ with a radiolabeled enkephalin analogue $\left(\left[{ }^{3} \mathrm{H}\right]\right.$ Tyr-DAla ${ }^{2}$-Leu-enkephalin $(20 \mathrm{nM}$, final volume $100 \mu \mathrm{l})$. We measured the protein concentration in each sample by the method of Bradford (16) and expressed enzyme activity as fmol $\times \min ^{-1} \times \mathrm{mg}$ protein $^{-1}$. To determine whether substrate degradation was due to NEP, we measured enzyme activity in the absence and presence of the NEP inhibitor leucine-thiorphan $\left(10^{-7} \mathrm{M}\right.$, a gift of E. R. Squibb \& Sons Pharmaceuticals, Princeton, NJ).

To express the substance $P$ dose-response curves with a single number that could be used for statistical analysis, we calculated the noncumulative dose of substance $P$ that would be required to increase $R_{L}$ by $200 \%$ above baseline by log-linear interpolation and called this value the $P D_{200}$. To quantify the magnitude of the effect of phosphoramidon on bronchomotor responsiveness to substance $P$, we calculated the ratio of the $P_{200}$ before phosphoramidon to the $P D_{200}$ after phosphoramidon for each animal $\left(\mathrm{PD}_{200}\right.$ ratio). We used Student's $t$ test for unpaired data to compare values for $\mathrm{PD}_{200}$ in air and TDI-exposed animals before and after phosphoramidon. We used the same test to compare $\mathrm{PD}_{200}$ ratios of animals exposed to air with those of animals exposed to TDI, and to compare the tissue NEP activity from animals exposed to air and to TDI. We compared values of PD $_{200}$ before phosphoramidon to values after phosphoramidon with Student's $t$ test for paired data.

\section{Results}

Phosphoramidon caused a significant leftward shift of the substance $\mathbf{P}$ dose-response curve in animals exposed to air $\left(\mathbf{P D}_{200}\right.$ $1.01+0.20 \mu \mathrm{g}$ [mean + GSEM] before phosphoramidon and $0.29+0.04$ after, $P<0.001 ; P_{200}$ ratio $3.5 \pm 0.3$ [mean \pm SEM]) (Figs. 1-3). In animals exposed to TDI, initial responsiveness to substance $P$ was significantly increased (initial $\mathrm{PD}_{200}, 0.40+0.06 \mu \mathrm{g}$ after TDI compared with 1.01 +0.20 after air, $P<0.001$ ) but the leftward shift in the substance $P$ dose-response curve caused by phosphoramidon was significantly reduced $\left(\mathrm{PD}_{200}\right.$ ratio $1.9 \pm 0.3$ after TDI compared with $3.5 \pm 0.3$ after air, $P<0.003$, Fig. 3). Furthermore, after phosphoramidon, substance $P$ responsiveness in animals exposed to TDI was not significantly different from substance $P$ responsiveness in animals exposed to air $(0.23+.03 \mu \mathrm{g}$ after TDI compared with $0.29+.04$ after air, Fig. 2 ).

NEP activity in the tracheas of animals exposed to TDI was significantly less than in the tracheas of animals exposed to air $\left(1,670 \pm 100 \mathrm{fmol} \times \mathrm{min}^{-1} \times \mathrm{mg}\right.$ protein $^{-1}$ (mean \pm SEM) after TDI exposure and 2,360 \pm 140 after air exposure, $P<0.002$, Fig. 4). More than $92 \%$ of the enzyme activity measured in the tracheas was inhibited by $10^{-7} \mathrm{M}$ leucine-thiorphan, an inhibitor of NEP, suggesting that the activity measured by our assay was specific. Enkephalin degrading activity in the esophagus was similar for animals exposed to TDI and air $(76 \pm 13 \mathrm{fmol}$

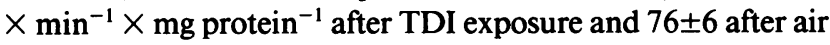
exposure).

\section{Discussion}

The results of the present study suggest that the contractile response of airway smooth muscle to substance $P$ is modulated in vivo by airway NEP activity. Thus, in healthy guinea pigs exposed to filtered air, phosphoramidon, an inhibitor of this enzyme, caused a nearly fourfold increase in bronchoconstrictor sensitivity to substance $P$. This study also showed that exposure to TDI significantly increased bronchoconstrictor sensitivity to substance $P$. That this effect of TDI was largely due to inhibition of NEP activity is suggested by our observation that after treatment with phosphoramidon bronchoconstrictor responsiveness to substance $P$ was the same in air-exposed and TDI-exposed animals, and by the decreased 

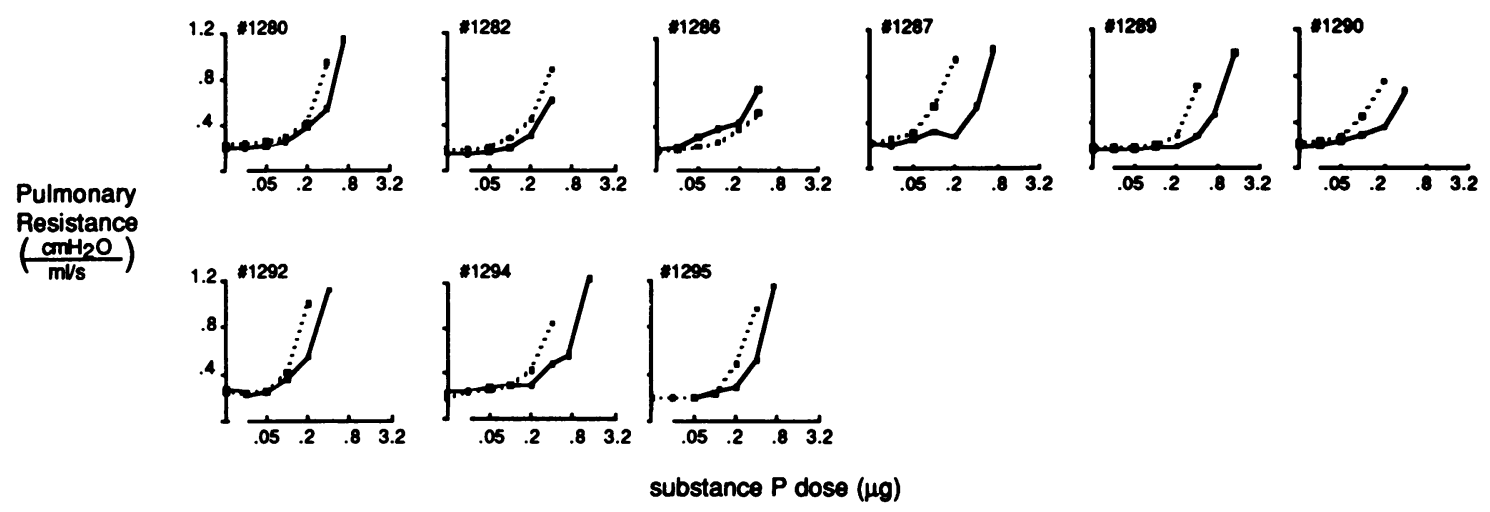

Air
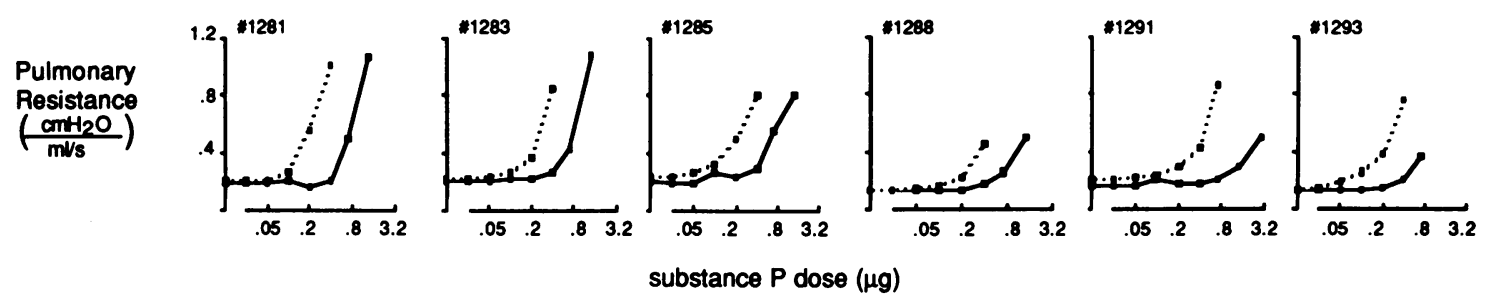

Figure 1. Individual dose-response curves plotting the increases in pulmonary resistance caused by intravenous administration of increasing doses of substance $\mathrm{P}$ before (solid lines) and after (dotted lines) intravenous administration of phosphoramidon ( $0.5 \mathrm{mg})$. Upper panel shows curves in animals exposed to TDI and lower panel shows curves in animals exposed to filtered air.
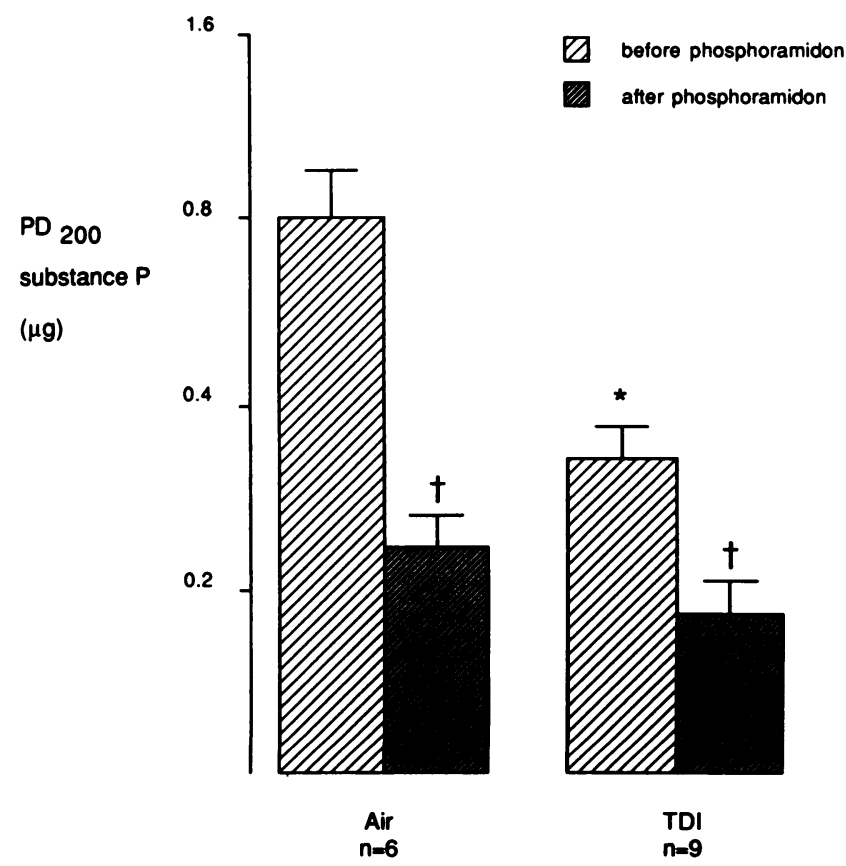

Figure 2. Mean (+GSEM) values for the dose of substance $P$ calculated to cause a $200 \%$ increase in pulmonary resistance above baseline $\left(\mathrm{PD}_{200}\right.$ substance $\left.\mathrm{P}\right)$ before and after phosphoramidon in animals studied after exposure to air or to TDI. ${ }^{*} \mathrm{PD}_{200}$ substance $\mathrm{P}$ significantly less than $\mathrm{PD}_{200}$ after air exposure and before phosphoramidon, $P<0.001$. $\ddagger$ Significantly lower than value before phosphoramidon, $P<0.01$. response to phosphoramidon in TDI-exposed animals. Furthermore, inhalation of TDI caused a reduction in the activity of NEP in the airway. These results thus suggest not only an important role for this enzyme in modulating airway responses under normal conditions, but also that alterations in NEP activity have a role in causing abnormal sensitivity to the bronchoconstrictor effects of substance $P$.

Although NEP derived its original name (enkephalinase) from observations that showed that it is involved in regulating effects of opioid peptides, it is now apparent that this enzyme is also highly active in cleaving several other small peptides,

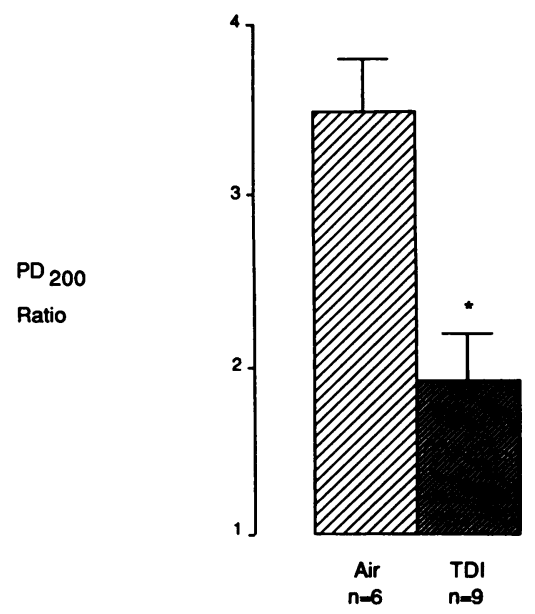

Figure 3. Mean $( \pm$ SEM) values of the ratio of the dose of substance $P$ required to increase pulmonary resistance by $200 \%$ above baseline before phosphoramidon to the dose required to produce the same effect after phosphoramidon $\left(\mathrm{PD}_{200}\right.$ ratio) for animals exposed to air or to TDI. *Significantly lower than value for animals exposed to air, $P$ $<0.003$. 

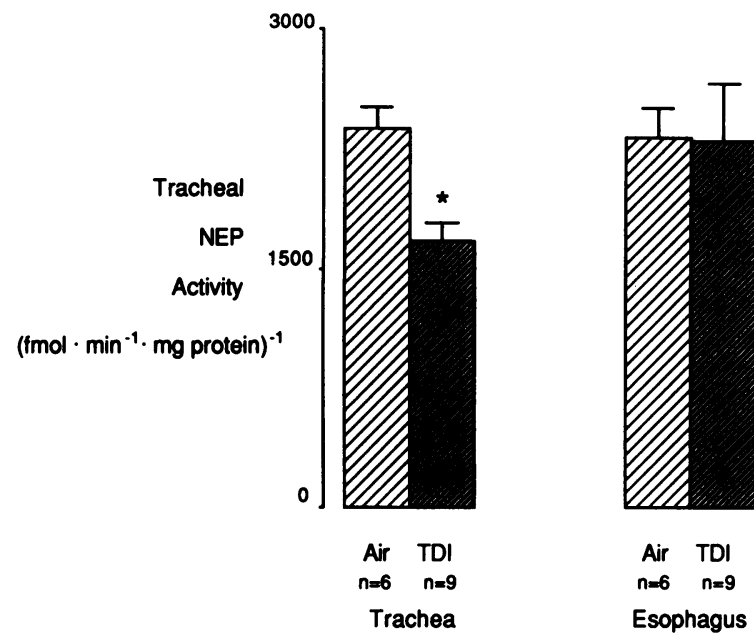

including substance $P$ and other tachykinins $(8,9)$. Thus, in in vitro studies, inhibition of NEP with either phosphoramidon or thiorphan caused a large increase in the effect of substance $P$ on output of sulfate-labeled macromolecules from ferret trachea (5). Similarly, inhibition with thiorphan caused a marked increase in the contractile effects of substance $P$, neurokinin $A$, and neurokinin $B$ on ferret tracheal smooth muscle, and caused a marked augmentation of the effects of subthreshold concentrations of these tachykinins in potentiating the contractile effects of electrical field stimulation (10). The results of the present study extend these in vitro observations to the contractile effects of substance $P$ on airway smooth muscle in vivo.

Toluene diisocyanate is a widely used industrial chemical that is also a well known cause of asthma in exposed workers. Because of its high vapor pressure, TDI vapor can rapidly accumulate in high concentrations in the air near accidental spills. It has been suggested that exposure to frequent spills is an important risk factor for the development of TDI-induced asthma (17). In guinea pigs, exposure to $3 \mathrm{ppm}$ TDI has been previously shown to produce morphologic evidence of superficial airway epithelial injury, characterized by a loss of cilia from surface cells and increased sloughing of epithelial cells into the airway lumen. This injury is rapidly followed by accumulation of inflammatory cells, initially primarily polymorphonuclear leukocytes, within the airway wall (12). In association with these morphologic signs of airway epithelial injury and inflammation, animals exposed to TDI have been shown to develop an increase in bronchoconstrictor responsiveness to inhaled and intravenous acetylcholine and to histamine (12, 18). Tachykinins contribute to this increase in bronchoconstrictor responsiveness, since the effects of TDI on acetylcholine responsiveness can be blocked by tachykinin depletion with capsaicin and by the administration of a tachykinin antagonist (7). The results of the present study demonstrate that TDI exposure also increases bronchoconstrictor responsiveness to intravenous substance $P$. This effect is not merely a manifestation of increased "nonspecific" bronchoconstrictor responsiveness, but rather appears to be a result of a decrease in NEP activity: when this enzyme was further inhibited by phosphoramidon, bronchoconstrictor responsiveness in animals exposed to TDI was not different from responsiveness in animals exposed to air.
Esophageal

NEP

Activity

$\left(\mathrm{fmol} \cdot \mathrm{min}^{-1} \cdot \mathrm{mg} \text { protein }\right)^{-1}$

Figure 4. Mean ( \pm SEM) values for NEP activity in the trachea (left columns) and esophagus (right columns) of animals exposed to air or to TDI. *Significantly less than value for animals exposed to air, $P<0.002$.
The present study did not examine the relationship, if any, between NEP inhibition and the TDI-induced increase in responsiveness to bronchoconstrictor stimuli other than substance $P$. Since, as noted above, tachykinins seem to play a critical role in the TDI-induced increase in acetylcholine responsiveness, such a relationship seems likely. One possible link between NEP inhibition and bronchoconstrictor responses to acetylcholine and to histamine is the report that both of these drugs may cause bronchoconstriction in guinea pigs in part by stimulating the release of tachykinins such as substance $P$ (19).

We presume that NEP inhibition potentiated the bronchoconstrictor effect of substance $P$ in the present study by inhibiting local breakdown of substance $P$ in the airways. Limitation of TDI's effect on NEP activity in the airways is supported by the observation that enzyme activity in the esophagus was the same in animals exposed to TDI as in animals exposed to air. However, because substance $P$ is not the only substrate for NEP, we cannot rule out the possibility that NEP inhibition altered substance $P$ responsiveness indirectly by decreasing the breakdown of some other substrate present in the vicinity of airway smooth muscle. It is not likely that such an effect was due to decreased breakdown of enkephalins themselves, though, since enkephalins would be expected to diminish, rather than potentiate, bronchoconstriction $(20,21)$.

The present study did not directly examine the mechanism(s) by which TDI inhibits NEP activity. TDI itself is a highly reactive molecule capable of interacting with a wide variety of biomolecules including proteins. Isocyanates have been reported to inactivate other proteinases, including chymotrypsin and elastase (22). It is thus conceivable that TDI directly inactivated NEP in the airways. Because this enzyme is present on the surface of airway cells, it may be especially sensitive to the effects of reactive molecules within the airway lumen. Alternatively, it is possible that TDI inactivated NEP indirectly as a result of the consequences of airway injury and inflammation (e.g., by leading to release of other proteolytic enzymes or toxic oxygen metabolites into the extracellular milieu).

Several agents other than TDI have been shown to increase the in vivo responsiveness of airway smooth muscle acutely in association with morphologic evidence of airway injury and inflammation (23-25). Airway epithelial injury is also a com- 
mon feature of human asthma (26), a disease characterized by abnormally increased airway responsiveness to bronchoconstrictors. The results of the present study suggest that inactivation of NEP may be one of the mechanisms by which airway injury contributes to bronchoconstrictor hyperresponsiveness.

\section{Acknowledgments}

The authors thank David Rose for preparation of the manuscript and graphics.

This work was supported in part by grants HL-33259 and HL-24136 from the National Heart, Lung, and Blood Institute.

\section{References}

1. Lundberg, J. M., T. Hokfelt, C. R. Marting, A. Saria, and C. Cuello. 1984. Substance $P$ immunoreactive sensory nerves in the lower respiratory tract of various mammals including man. Cell Tissue Res. 235:251-261.

2. Lundberg, J. M., E. Brodin, and A. Saria. 1983. Effects and distribution of vagal capsaicin sensitive neurons with special reference to the trachea and lungs. Acta Physiol. Scand. 119:243-252.

3. Lundberg, J. M., A. Saria, E. Brodin, S. Rosell, and R. Folkers. 1983. A substance $P$ antagonist inhibits vagally induced increase in vascular permeability and bronchial smooth muscle contraction in the guinea pig. Proc. Natl. Acad. Sci. USA. 80:1120-1124.

4. Lundberg, J. M., and A. Saria. 1983. Capsaicin-induced desensitization of the airway mucosa to cigarette smoke, mechanical and chemical irritants. Nature (Lond.). 302:251-253.

5. Borson, D. B., R. Corrales, S. Varsano, M. Gold, N. Viro, G. Caughey, J. Ramachandran, and J. Nadel. 1987. Enkephalinase inhibits potentiating substance P-induced release of ${ }^{35} \mathrm{SO}_{4}$ macromolecules from ferret trachea. Exp. Lung Res. 12:21-36.

6. Grunstein, M., D. Tanaka, and J. Grunstein. 1984. Mechanism of substance P-induced bronchoconstriction in maturing rabbit. $J$. Appl. Physiol. 57:1238-1246.

7. Thompson, J. E., L. Scypinski, T. Gordon, and D. Sheppard. 1987. Tachykinins mediate toluene diisocyanate induced airway hyperresponsiveness in guinea pigs. Am. Rev. Respir. Dis. 136:43-49.

8. Matsas, R., I. S. Fulcher, A. J. Kenny, and A. J. Turner. 1983. Substance $P$ and [Leu] enkephalin are hydrolized by an enzyme in pig caudate synaptic membranes that is identical with the endopeptidase of kidney microvilli. Proc. Natl. Acad. Sci. USA. 80:3111-3115.

9. Matsas, R., M. Rattray, A. J. Kenny, and A. J. Turner. 1985. The metabolism of neuropeptides. Biochem. J. 228:487-492.

10. Sekizawa, K., J. Tamoki, J. A. Nadel, D. B. Borson. 1987. Enkephalinase inhibitor (leucine-thiorphan) potentiates mammalian tachykinin-induced contraction in ferret trachea. Fed. Proc. 46:650. (Abstr.)

11. Borson, D. B., B. Malfroy, M. Gold, J. Ramachandran, and
J. A. Nadel. 1986. Tachykinins inhibit enkephalinase activity from trachea and lungs of ferrets. Physiologist. 29:174. (Abstr.)

12. Gordon, T., D. Sheppard, D. McDonald, L. Scypinski, and S. Distefano. 1985. Airway hyperresponsiveness and inflammation induced by toluene diisocyanate in guinea pigs. Am. Rev. Respir. Dis. 132:1106-1112.

13. Amdur, M. O., and J. Mead. 1958. Mechanics of respiration in unanesthetized guinea pigs. Am. J. Physiol. 192:364-368.

14. Marcali, K. 1957. Microdetermination of toluene diisocyanate in atmosphere. Anal. Chem. 29:552-558.

15. Llorens, C. B., B. Malfroy, J. C. Schwartz, G. Gacel, B. P. Roques, J. Roy, J. L. Morgat, F. Javoy-Agid, and Y. Agid. 1982. Enkephalin dipeptidyl carboxy-peptidase (enkephalinase) activity: selective radioassay, properties, and regional distribution in human brain. J. Neurochem. 39:1081-1089.

16. Bradford, M. M. 1976. A rapid and sensitive method for the quantitation of microgram quantities of proteins utilizing the principle of protein-dye binding. Anal. Biochem. 72:248-254.

17. Brooks, S. M. 1982. The evaluation of occupational airways disease in the laboratory and workplace. J. Allergy Clin. Immunol. 70:50-66.

18. Cibulas, W., C. G. Murlas, M. L. Miller, A. Vinegar, D. S. Schmidt, R. T. McKay, I. L. Bernstein, and S. M. Brooks. 1986. Toluene diisocyanate-induced airway hyperreactivity and pathology in the guinea pig. J. Allergy Clin. Immunol. 77:828-834.

19. Martling, C. R., A. Saria, P. Andersson, and J. M. Lundberg. 1984. Capsaicin pre-treatment inhibits vagal cholinergic and non-cholinergic control of pulmonary mechanics in the guinea pig. NaunynSchmiedeberg's Arch. Pharmacol. 325:343-348.

20. Eschenbacher, W. L., R. A. Bethel, H. A. Boushey, and D. Sheppard. 1984. Morphine sulfate inhibits bronchoconstriction in subjects with asthma whose responses are inhibited by atropine. $\mathrm{Am}$. Rev. Respir. Dis. 130:363-367.

21. Russell, J. A., and E. J. Simons. 1985. Modulation of cholinergic neurotransmission in airways by enkephalin. J. Appl. Physiol. 58:853-858.

22. Brown, W. E., and F. Wold. 1971. Alkyl isocyanates as activesite specific inhibitors of chymotrypsin and elastase. Science (Wash. DC). 174:608-610.

23. Holtzman, M. J., L. M. Fabbri, P. M. O’Byrne, B. D. Gold, H. Aizawa, E. H. Walters, S. E. Albert, and J. A. Nadel. 1983. Importance of airway inflammation for hyperresponsiveness induced by ozone in dogs. Am. Rev. Respir. Dis. 127:686-690.

24. Hulbert, W. C., T. McLean, and J. C. Hogg. 1985. The effect of acute airway inflammation on bronchial reactivity in guinea pigs. Am. Rev. Respir. Dis. 132:7-11.

25. Chung, K. F., A. B. Becker, S. C. Lazarus, O. L. Frick, J. A. Nadel, and W. M. Gold. 1985. Antigen-induced airway hyperresponsiveness and pulmonary inflammation in allergic dogs. J. Appl. Physiol. 58:1347-1353.

26. Laitinen, L., M. Heino, A. Laitinen, T. Kava, and T. Haahela. 1985. Damage of the airway epithelium and bronchial reactivity in patients with asthma. Am. Rev. Respir. Dis. 131:599-606. 